\title{
Formation and Emission of Tetraalkylammonium Salt Molecular Ions Sputtered from a Gelatin Matrix
}

\author{
Joe Bennett and Greg Gillen \\ Surface and Microanalysis Science Division, National Institute of Standards and Technology, \\ Gaithersburg, Maryland, USA
}

\begin{abstract}
A gelatin matrix was simultaneously doped with nine equimolar, homologous, tetraalkylammonium salts ranging in mass from 210 to $770 \mathrm{Da}$. Bombardment of the sample with kiloelectronvolt ions resulted in a nonidentical distribution of relative cation intensities with a maximum at $m / z 242$ for samples with a total salt concentration of $0.004 \mathrm{~g}$ of salt $/ \mathrm{g}$ of gelatin. A rapid increase in relative intensities with increasing mass is observed for the low mass salts and is believed to be linked to changes in the ionization efficiencies. The changes in ionization efficiencies are likely related to decreasing coulombic attractive forces between the organic cation and the counterion. Disappearance cross sections, determined from decay curves, indicate that sputter-induced damage increases with increasing mass of the cation. Fragment- to-intact cation ratios also suggest that damage accumulates fastest in the heaviest salts. These observations indicate that desorption yields of the organic salts in a gelatin matrix decrease with increasing mass. In addition, suppression of lower mass tetraalkylammonium salt intact cation intensities was observed for salt-in-gelatin concentrations greater than $10^{-3} \mathrm{~g} / \mathrm{g}$. (J Am Soc Mass Spectrom 1993, 4, 930-937)
\end{abstract}

$\mathrm{T}$ he production of molecular and structurally significant fragment ions from Ilonvolatile, thermally labile organic compounds under kiloelectronvolt ion or atom bombardment $[1,2]$ has found practical use in many diverse areas including polymer characterization [3], biomaterial analysis [4], and surface modification studies [5]. However, despite the increasing utility of organic secondary ion mass spectrometry (SIMS), a comprehensive description of the complex mechanisms involved in the sputter-induced formation and emission of secondary ions from organic compounds has yet to emerge.

Complications associated with developing a model of the ion production process in SIMS are related to difficulties in measuring fundamental parameters that are important in the sputtering process such as sputter or desorption yiclds and ion yields. In elemental SIMS, where the sputtering theory is better developed, the determination of these parameters is simplified by the use of well-characterized, homogeneous samples. Samples of this type are generally not available for organic SIMS. Variations in sample preparation can affect secondary ion signals, making absolute quantitative determinations of ion and sputter yields difficult. Another complication arises from the presence of primary ion-induced damage to the sample molecule during

Address reprint requests to Dr. Joe Bennett, Surface and Microanalysis Science Division. National Institute of Standards and Technology, Building 222, Room A113, Gaithersburg, MD 20899. sputtering. Ordinarily, organic SIMS is performed under stalic conditions (i.e., the total primary ion dose is kept below $10^{13}$ ions $/ \mathrm{cm}^{2}$ ), keeping sample damage to a minimum [6]. As the dose increases the intensity of the molecular ion begins to decrease. However, the changes observed in the intensities of a molecular secondary ion as a function of primary ion dose are not the same for all compounds and depend on the sputter yield and damage rate of the compound. It is often difficult to distinguish between the two. One parameter used to investigate the influence of sputter yields and damage rates on the formation and emission of molecular ions is the disappearance cross section. The disappearance cross section is a measure of the area on the surface perturbed by the bombarding species and describes the removal of a surface molecule through sputtering or damage. Some of the best measurements of organic SIMS sputtering parameters have been made on samples prepared by controlled deposition of small biological compounds on metal surfaces under ultra high vacuum conditions [7]. However, not all compounds are amenable to this method of sample preparation. Studies by Cooks and Busch and Ross and Colton addressed the effects of different matrices on the desorption and ionization of preformed ions [8] and polyaromatic hydrocarbon species [9] in an effort to gain more information about the mechanism of ion production in organic SIMS.

In recent year's the identification and localization of biologically important organic molecules in tissue has 
drawn considerable interest $[10,11]$, but has been hampered by the limited knowledge about the ion formation and emission processes in tissue. In an attempt to better understand the fundamentals of secondary ion production in tissue we are investigating the formation and emission of organic molecular ions from a tissuelike, gelatin matrix. Gelatin films have been successfully used as model systems in fundamental studies of the emission of elemental species [12] and, more recently, organic species $[13,14]$ from biological matrices. In addition to gaining information about the behavior of organic compounds in a tissuelike matrix, the use of the gelatin matrix provides the following advantages over the analysis of neat compounds: (1) variations in secondary ion signals due to coverage effects (e.g., lateral inhomogeneities, segregation into islands) are minimized, and (2) the concentrations of the species can be varied. Early studies with the gelatin matrix provided information on the uniformity of distribution, detection limits and sensitivities for a series of biologically important compounds doped in gelatin films [15]. We are continuing our investigations into the use of a gelatin matrix for fundamental organic SIMS studies and report here on the contributions of ion and desorption yields and damage rates to secondary ion signals observed for a mixture of tetraalkylammonium salts doped in gelatin.

\section{Experimental}

\section{Instrumental}

The data presented here were collected on a Kratos 401LS time-of-flight secondary ion mass spectrometer. ${ }^{*}$ The samples were bombarded with 22 kiloelectronvolt $\mathrm{Ga}^{+}$from an isotopically enriched $\mathrm{Ga}$ liquid metal ion source $\left(>99 \%{ }^{69} \mathrm{Ga}\right)$. The continuous primary ion beam current for a $1 \mu \mathrm{m}$ diameter beam was $\sim 530 \mathrm{pA}$. The secondary ion mass spectra were obtained by pulsing the primary ion beam (pulse duration $50 \mathrm{~ns}$; each pulse contains about 150 ions) while maintaining the sample at a constant bias of $3 \mathrm{kV}$. The repetition rate of the gun was $7.5 \mathrm{kHz}$. Secondary ions were extracted into the grounded, reflection-type time-of-flight mass spectrometer (flight length $\sim 3 \mathrm{~m}$ ). The secondary ions were detected by a dual microchannel plate detector with no postacceleration. The signal from the detector was fed to a multistop time-to-digital converter (TDC) with $10 \mathrm{~ns}$ time resolution. A mass resolution of $\mathrm{M} / \Delta \mathrm{M} \approx 1000$ (FWHM) was measured at $m / z 410$. The positive ion mass spectra were acquired from rastered areas of $500 \mu \mathrm{m} \times 500 \mu \mathrm{m}$ using a total

\footnotetext{
* Certain commercial equipment, instruments, or materials are identified in this article to specify the experimental procedure. Such identi fication does not imply recommendation or endorsement by the $\mathrm{Na}$ tional Institute of Standards and Technology, nor does it imply that the materials or equipment are necessarily the best available for the purpose.
}

primary ion dose of about $10^{11}$ ions $/ \mathrm{cm}^{2}$ (static SIMS conditions).

In this study, secondary ion decay curves were obtained by alternating between continuous primary ion beam sputtering and pulsed beam data acquisition. A $500 \mu \mathrm{m} \times 500 \mu \mathrm{m}$ area was exposed to the rastered, continuous ion beam for short periods of time. The continuous beam was then blanked and positive secondary ion mass spectra were collected under pulsed beam conditions from a smaller area $(200 \mu \mathrm{m} \times 200$ $\mu \mathrm{m}$ ) within the previously sputtered area. This method reduced the influence of the crater walls on the secondary ion intensities. The dose used to collect the secondary ion spectrum after each continuous beam sputter cycle was about $4-6 \times 10^{11}$ ions $/ \mathrm{cm}^{2}$.

\section{Sample Preparation}

The analyte-gelatin samples were prepared by spincasting solutions of tetraalkylammonium salts (either individually or as a mixture) and porcine gelatin onto $1-\mathrm{cm}^{2}$ pieces of $\mathrm{Si}$. The Si provides a readily available polished, conductive surface that is easily cleaned. The salts came from a homologous series of nine tetraalkylammonium bromide compounds ranging in mass from 210 to $770 \mathrm{Da}$ (see Table 1). Tetraethyl-, tetrabutyl-, tetrapentyl-, tetrahexyl-, and tetraheptylammonium bromide were obtained from Aldrich Chemical Company. Tetrapropyl- and tetradodecylammonium bromide were obtained from Fluka Chemical Corporation. Tetraoctyl- and tetradecylammonium bromide were obtained from Sigma Chemical Company. All compounds were used as received. The salt-gelatin solutions were prepared by transferring aliquots of individual salts dissolved in $95 \%$ ethanol (salt concentration $\sim 10^{-3} \mathrm{~mol} / \mathrm{L}$ ) to $90 \mathrm{~mL}$ of heated 1:1 $\mathrm{H}_{2} \mathrm{O}$ : ethanol (95\%) into which $\sim 1 \mathrm{~g}$ of type A porcine gelatin (300 bloom, Sigma Chemical Company \#G2500 ) had been dissolved. The gelatin had been oven dried at $60^{\circ} \mathrm{C}$ for 24 hours before weighing. A single drop from the salt-gelatin solution was deposited onto a piece of spinning Si. The spin casting procedure has been described previously [13, 15]. Because no molecular weight is available for the gelatin matrix, the salt concentrations in the gelatin matrices will be reported in mass of all salts per mass of (dry) gelatin. Dynamic SIMS depth profiles of the counter ion $\left(\mathrm{Br}^{-}\right)$did not show any significant intensity variations over the thickness of the films. This indicates that the salts were homogeneously distributed throughout the films. Lateral homogeneity was confirmed by imaging SIMS as described in a previous study [15].

\section{Results and Discussion}

The tetraalkylammonium salts were chosen for several reasons: (1) direct emission of positively charged intact cations from the preformed salts is highly efficient and results in sensitive detection of the compounds [16]; (2) 
Table 1. Intact cation and fragment ion masses and fragment-to-cation ratios for tetraalkylammonium salts*

\begin{tabular}{|c|c|c|c|c|c|c|c|}
\hline & & \multicolumn{3}{|c|}{ Mass $(m / z)$} & \multirow[b]{2}{*}{$\begin{array}{l}\text { Fragment -to- } \\
\text { Cation Ratio }\end{array}$} & \multirow{2}{*}{$\begin{array}{c}\text { Disappearance } \\
\text { Cross Section, } \sigma \\
\left(10^{-14} \mathrm{~cm}^{2}\right)\end{array}$} & \multirow{2}{*}{$\begin{array}{l}\text { Slope from } \\
\text { Fragment -to- } \\
\text { Cation Ratios } \\
\left(10^{-14} \mathrm{~cm}^{2}\right)\end{array}$} \\
\hline \multicolumn{2}{|c|}{ Ammonium Salt } & $\begin{array}{l}\text { Intact Cation } \\
\mathrm{R}_{\mathbf{4}} \mathrm{N}^{+}\end{array}$ & $\begin{array}{l}\operatorname{Iminium}_{2} \mathrm{R}_{2} \mathrm{~N}^{+}=\mathrm{CH}_{2} \\
\end{array}$ & $\mathbf{R}_{2} \mathbf{N}^{+}=(\mathbf{R}-\mathrm{H})$ & & & \\
\hline Tetraethyl & $\left(\mathrm{Et}_{4} \mathrm{~N}^{+}\right)$ & 130 & 86 & 100 & - & - & - \\
\hline Tetrapropyl & $\left(\mathrm{Pr}_{4} \mathrm{~N}^{+}\right)$ & 186 & 114 & 142 & - & 3.2 & - \\
\hline Tetrabutyl & $\left(\mathrm{Bu}_{4} \mathrm{~N}^{+}\right)$ & 242 & 142 & 184 & 0.82 & 6.6 & 1.6 \\
\hline Tetrapenty! & $\left(\mathrm{Pe}_{4} \mathrm{~N}^{+}\right)$ & 298 & 170 & 226 & 0.77 & 7.6 & 3.2 \\
\hline Tetrahexyl & $\left(\mathrm{Hx}_{4} \mathrm{~N}^{+}\right)$ & 354 & 198 & 268 & 0.90 & 8.9 & 3.4 \\
\hline Tetrahepty| & $\left(\mathrm{Hp}_{4} \mathrm{~N}^{+}\right)$ & 410 & 226 & 310 & - & 10.4 & $-\infty$ \\
\hline Tetraoctyl & $\left(0 c_{4} N^{+}\right)$ & 466 & 254 & 352 & 0.99 & 11.5 & 5.3 \\
\hline Tetradecyl & $\left(\mathrm{De}_{4} \mathrm{~N}^{+}\right)$ & 578 & 310 & 436 & - & 13.0 & - \\
\hline Tetradodecyl & $\left(\operatorname{Dode}_{4} \mathrm{~N}^{+}\right)$ & 690 & 366 & 520 & 2.1 & 14.7 & 6.1 \\
\hline
\end{tabular}

* The intact cation disappearance cross sections are from the decay curves in Figure 5 and the slopes are from linear fits to the fragment-to-cation ratio curves found in Figure 6.

** Used in calculating fragment-to-cation ratio.

tetraalkylammonium salts are available in a homologous series over a wide mass range; and (3) previous work on tetraalkylammonium salts provides a database of information on cation formation and fragmentation [17-22] mostly from field desorption-collision-activated dissociation mass spectrometry studies. A series of gelatin films, in which each film, contained an equimolar amount of only one salt, showed the presence of the intact cation and demonstrated that fragment ions from higher mass salts do not significantly interfere with lower mass cations. Table 1 lists the intact cation masses and the mass of the two most intense fragment ions observed for each compound. An undoped gelatin film, used as a blank, showed major secondary ion peaks at $m / z 70$ and 86 . A discrete background is present out to around $m / z 180$, but beyond that no significant secondary ions are observed. Figure 1 shows the mass region around the intact cations of $\operatorname{Pr}_{4} \mathrm{~N}^{+}$

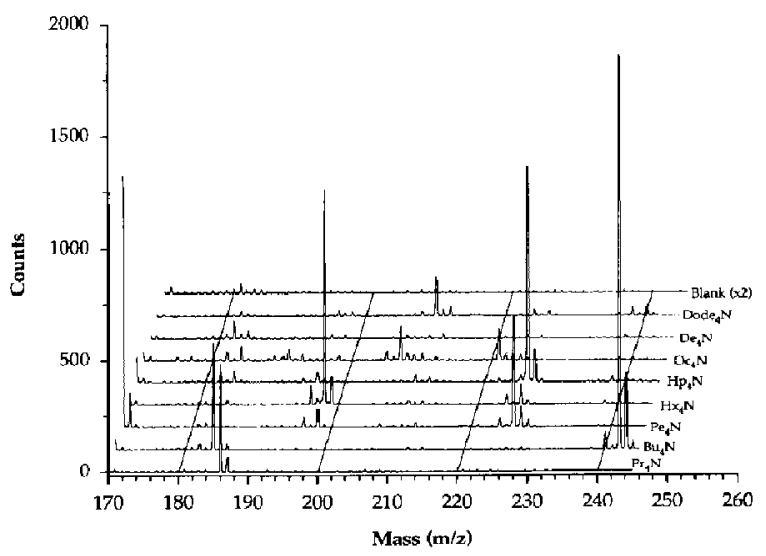

Figure 1. Positive secondary ion mass spectra from eight different gelatin films, each doped with a single tetraalkylammonium salt. An undoped gelatin film is included as a blank. The mass range displayed includes the intact cations of $\mathrm{Pr}_{4} \mathrm{~N}^{+}(\mathrm{m} / \mathrm{z}$ $186)$ and $\mathrm{Bu}_{4} \mathrm{~N}^{+}(m / z 242)$.
( $m / z$ 186) and $\mathrm{Bu}_{4} \mathrm{~N}^{+}(m / z 242)$ for eight salts and the blank. Interferences from high mass salt fragment ions and the blank account for about $10 \%$ of the total ion signal at $m / z 186$, with the majority of the interfering signal coming from a fragment ion of $\mathrm{Bu}_{4} \mathrm{~N}^{+}$. The interferences at $\mathrm{m} / \mathrm{z} 242$ contribute around $2 \%$ to the total signal. Interferences never exceed $4 \%$ for any of the other intact cations. For $\mathrm{Et}_{4} \mathrm{~N}^{+}$, the background ion signal from the gelatin matrix makes assignment ambiguous. As can be seen in Table 1, some interferences also occur between the various fragment ions from different salts.

\section{Secondary Ion Peak Intensities}

A typical positive ion mass spectrum obtained from a gelatin sample doped with a mixture of nine equimolar salts is shown in Figure 2. The spectrum represents the collection of secondary ions produced during $2 \times$ $10^{6}$ ion gun pulses. The concentration of the sample was $0.004 \mathrm{~g}$ salt $/ \mathrm{g}$ gelatin. Absolute intact cation integrated signal intensities (i.e., the total number of secondary ions contained under a cation peak in the mass spectrum), varied from spot to spot on a single sample and were related to small variations in the uniformity and thickness of the gelatin films. However, relative intensities were within 10\% (relative standard deviation) for several analyses on a single sample. Samples prepared from the same initial solution show similar precision, but the variations can be greater $(40 \%)$ when data from different solutions are included. Intact cations for eight of the nine compounds were detected. The one salt not detected with confidence (for reasons given previously) was $\mathrm{Et}_{4} \mathrm{~N}^{+}$, the lowest mass species in the mixture.

A plot of the relative integrated intact cation signal intensities as a function of cation mass is show in Figure 3 . The intensities are expressed relative to $\mathrm{Hx}_{4} \mathrm{~N}^{+}$and have not been corrected for mass interferences. These values represent the average of the signal 

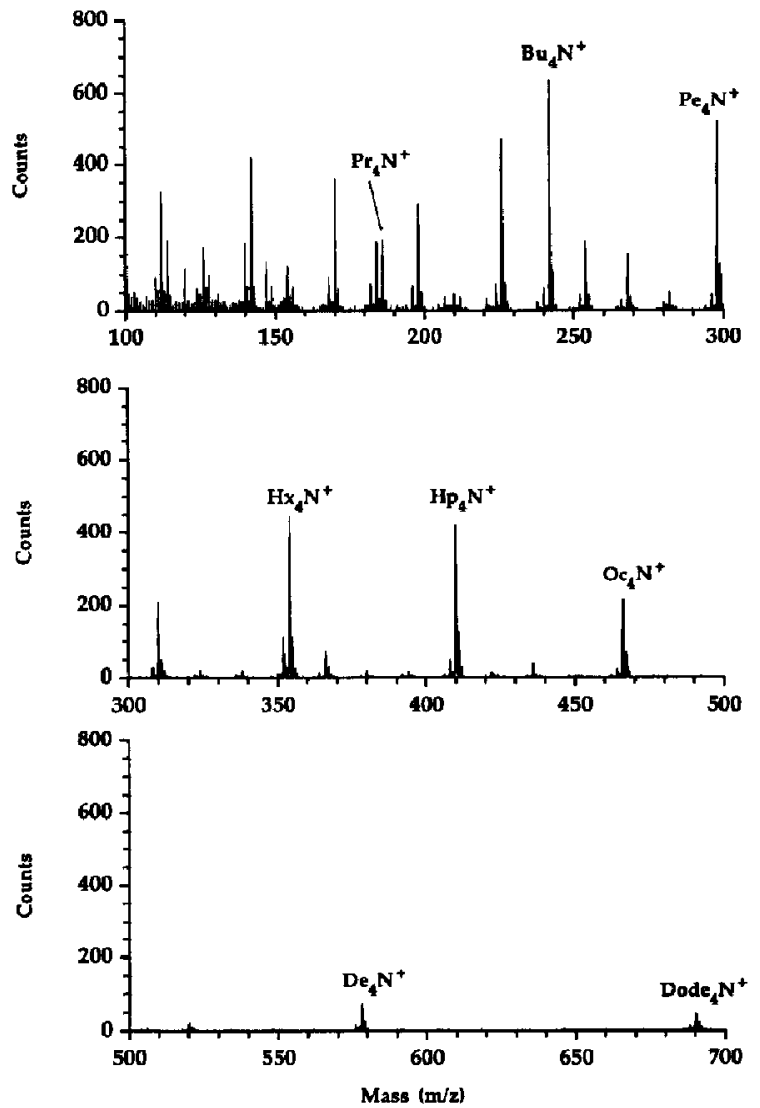

Figure 2. Positive secondary ion mass spectrum from a gelatin matrix doped with an equimolar mixture of nine tetraalkylammonium salts. Primary ion dose $=10^{11}$ ions $/ \mathrm{cm}^{2}$.

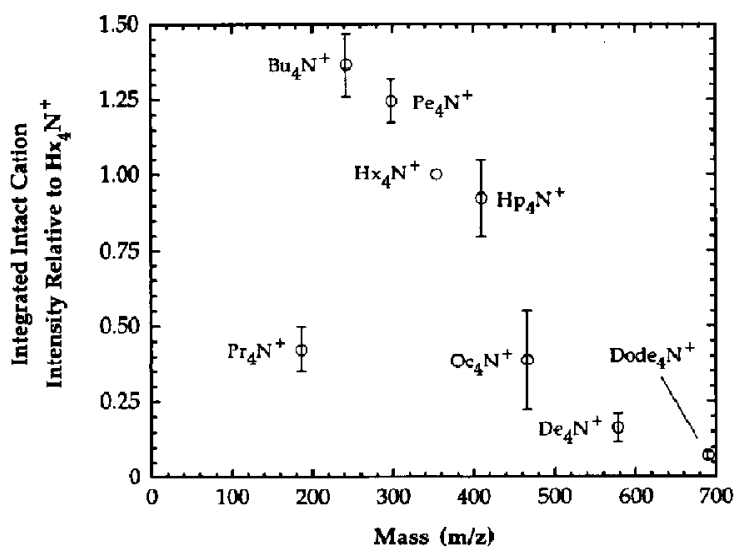

Figure 3. Intact cation integrated signal intensities relative to $\mathrm{Hx}_{4} \mathrm{~N}^{+}$from an equimolar mixture of tetraalkylammonium salts in gelatin as a function of cation mass. intensities for the eight intact cations from 26 mass spectra taken from five different samples. The error bars represent the standard deviations (s) of the individual measurements. The total salt content in the gelatin samples ranged from $0.002-0.004 \mathrm{~g}$ salt $/ \mathrm{g}$ gelatin.

A simplistic view of the desorption/ionization process would suggest that the relative intensities of the intact cations sputtered from a matrix containing equimolar amounts of each salt should be nearly the same. However, the distribution of relative intensities shown in Figure 3 is not consistent with such a view and indicates that concentration is not the only factor influencing the formation and emission of intact cations from a gelatin matrix. One possible explanation for the inconsistency is that intact cations are lost through fragmentation, and that the degree of fragmentation varies. The most intense fragment ion formed during ion bombardment of tetraalkylammonium salts results from a two-step reaction involving dealkylation of the quaternary ammonium ion accompanied by $\alpha$ cleavage in a neighboring alkyl chain to produce an iminium ion $\left(\mathrm{R}_{2} \mathrm{~N}^{+}=\mathrm{CH}_{2}\right)$ [18]. The masses of the iminium ions resulting from this fragmentation pathway are listed in Table 1 as well as the fragment-tocation ralios oblained under static SIMS conditions. The ratios of the integrated signal intensities in the iminium ion peak and the intact cation peak provide information on the extent of fragmentation during ion bombardment. Interferences were present between the major iminium fragment ions of $\mathrm{Pr}_{4} \mathrm{~N}^{+}, \mathrm{Hp}_{4} \mathrm{~N}^{+}$and $\mathrm{De}_{4} \mathrm{~N}^{+}$and some of the less intense fragments from other salts; therefore, fragment-to-cation ratios for these three compounds were not determined. The ratios indicate that fragmentation is more prevalent for the heavier salts (Dode ${ }_{4} \mathrm{~N}^{+}$versus $\mathrm{Bu}_{4} \mathrm{~N}^{+}$). However, the extent of fragmentation observed for the salts does not account for the differences in intact cation intensities seen in Figure 3. The relative intact cation intensities for the salts from $\mathrm{Bu}_{4} \mathrm{~N}^{+}$to $\mathrm{Oc}_{4} \mathrm{~N}^{+}$vary by over a factor of three while the fragment-to-cation ratios vary by only $20 \%$. The relative intact cation intensity of Dode ${ }_{4} \mathrm{~N}^{+}$is down by a factor of almost 20 compared to $\mathrm{Bu}_{4} \mathrm{~N}^{+}$, but the fragment-to-cation ratio has increased only a factor of 2.5 from $\mathrm{Bu}_{4} \mathrm{~N}^{+}$to Dode $\mathrm{N}^{+}$. It appears that the variations in relative intact cation intensities cannot be completely accounted for by fragmentation.

\section{Emission of Molecular lons}

Having addressed the effects of fragmentation on intact cation intensities we will now describe the trends observed in Figure 3 as they relate to the three remaining factors that affect the formation and emission of molecular ions from the gelatin matrix, namely, ionization efficiency, primary ion-induced damage, and desorption yield variations. We will also discuss the effects of salt concentration on the relative intensities. 
Ionization effects. If we assume that the formation of the intact cation results from breaking the bond between the organic cation and inorganic counterion $\left(\mathrm{Br}^{-}\right)$then the process can be described using fundamental physical laws developed for classical ionic salts [23]. According to Coulomb's law (eq 1) the attractive force $(\mathrm{F})$ between two charges $\left(\mathrm{q}_{1}\right.$ and $\left.\mathrm{q}_{2}\right)$ is related to the distance $(r)$ separating the charges.

$$
F \propto \frac{q_{1} q_{2}}{r^{2}}
$$

To a first approximation, the size (or radius) of the ions defines the separation between the charges and thus controls the attractive forces. Therefore, as the ionic radii increase for a homologous series of molecules the attractive forces should decrease, and breaking the ionic bond should become easier [i.e., the ionization efficiency (ion yield) should increase]. This relationship was proposed by Colton and co-workers [24] to explain an observed trend of increasing intact cation abundances as a function of increasing mass for an equimolar solution of $\mathrm{Et}_{4} \mathrm{~N}^{+}, \mathrm{Pr}_{4} \mathrm{~N}^{+}, \mathrm{Bu}_{4} \mathrm{~N}^{+}$and $\mathrm{Pe}_{4} \mathrm{~N}^{+}$deposited onto a metal substrate. The calculation of Stokes radii of four tetraalkyl cations $\left(\mathrm{Me}_{4} \mathrm{~N}^{+}\right.$, $\mathrm{Et}_{4} \mathrm{~N}^{+}, \mathrm{Pr}_{4} \mathrm{~N}^{+}$, and $\mathrm{Bu}_{4} \mathrm{~N}^{+}$) from limiting conductances in water shows that the cation size does indeed increase with mass $\left(r \propto \mathrm{m}^{0.7}\right)$ [25]. Therefore, by invoking Coulomb's law to describe the fundamental attractive forces (and, inversely, the ionization efficiency) in the organic salts, we predict that the attractive forces would decrease with mass according to the $1 / \mathrm{r}^{2}$ relationship (or $1 / \mathrm{m}^{1.4}$ ). Figure 4 shows a plot of $1 / \mathrm{r}^{2}$ as a Function of cation mass for $\mathrm{Me}_{4} \mathrm{~N}^{+}$through $\mathrm{Bu}_{4} \mathrm{~N}^{+}$ where $r$ is the Stokes radius. Also shown in Figure 4 is a plot of the solution state dissociation constants $K$, defined as:

$$
K=\frac{\left[C^{+}\right]\left[A^{-}\right]}{\left[C^{+} A^{-}\right]^{0}}
$$

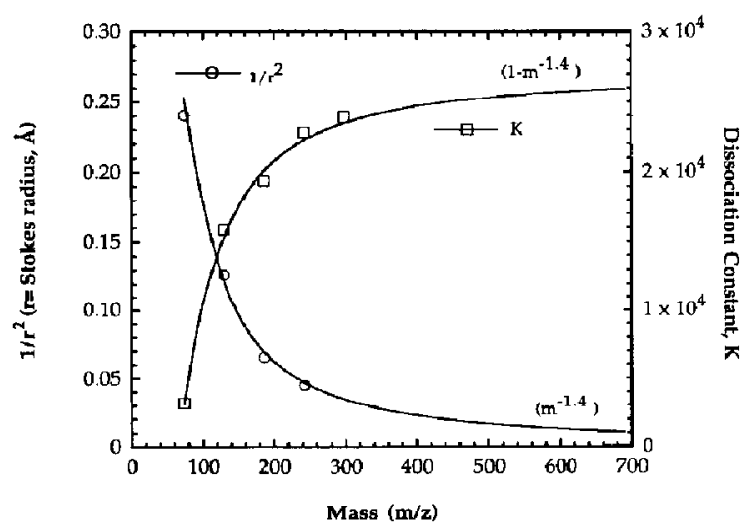

Figure 4. Plot of $1 / \mathrm{r}^{2} \quad(r=$ Stokes radius in $\hat{\Lambda}$ [25]) and the solution state dissociation constant [26], K, for several tetraalkylammonium salts. Sulid curves represent fits to the data according to $\mathrm{m}^{-1.4}$ and $1-\mathrm{m}^{-1.4}$ relationships. for five tetraalkylammonium salts as a function of their mass. If we assume that the dissociation of tetraalkylammonium salts into ion pairs in solution is related to the solvating properties of the solvent and the bond energy between the cation and counterion (the higher the dissociation constant the lower the bond energy) then changes in the solution state dissociation constant as a function of mass can be used to indicate changes in attractive forces. The dissociation constants in Figure 4 are for $\mathrm{Me}_{4} \mathrm{~N}^{\prime}, \mathrm{Et}_{4} \mathrm{~N}^{4}, \mathrm{Pr}_{4} \mathrm{~N}^{\prime}, \mathrm{Bu}_{4} \mathrm{~N}^{\prime}$ and $\mathrm{Pc}_{4} \mathrm{~N}^{+}$(counterion = picrate) in ethylene chloride [26]. The solid curves in Figure 4 represent fits to the data according to a $1-\mathrm{m}^{-1.4}$ relationship for the dissociation constants, $K$, and $\mathbf{a ~ m}^{-1.4}$ relationship for the $1 / \mathrm{r}^{2}$ values. As can be seen in Figure $4,1 / r^{2}$ and $K$ are changing rapidly for the lower mass salts $\left(\mathrm{Me}_{4} \mathrm{~N}^{+}\right.$and $\left.\mathrm{Et}_{4} \mathrm{~N}^{+}\right)$. Above $\mathrm{Pe}_{4} \mathrm{~N}^{+}(m / z 298)$ the $1 / \mathrm{r}^{2}$ and $\mathrm{K}$ values are expected to show smaller changes than the low mass salts. Since we are using $K$ and $1 / r^{2}$ to describe the strength of the attractive forces and inversely the ion yield, we would expect the differences between ionization efficiencies for salts larger than $\mathrm{Pe}_{4} \mathrm{~N}^{+}$to be less than the differences encountered for salts smaller than $\mathrm{Pe}_{4} \mathrm{~N}^{+}$. The low mass portion of the data in Figure 3 show similarities to the $1 / \mathrm{r}^{2}$ and dissuciation constant plots in Figure 4 . The rapid increase in intact cation intensities between $\operatorname{Pr}_{4} \mathrm{~N}^{+}$and $\mathrm{Bu}_{4} \mathrm{~N}^{+}$is consistent with the hypothesis that attractive forces are weakening and the ionization efficiencies are increasing with mass. In addition, the low intensity (or absence) of a signal at $m / z 130$ for $\mathrm{Et}_{4} \mathrm{~N}^{+}$supports the idea that higher bond strengths, and thus lower ion yields, are associated with the lower mass (smaller) species.

In an analogous study we obtained data on the effects of the size of the negative counter ion $\left(\mathrm{Cl}^{-}, \mathrm{Br}^{-}\right.$, $\mathrm{I}^{-}$, and $\mathrm{IO}_{4}^{-}$) on the yield of a single salt, $\mathrm{Bu}_{4} \mathrm{~N}^{+}$. Preliminary results indicate that there is no significant difference in the $\mathrm{Bu}_{4} \mathrm{~N}^{+}$yield for any of the negative ions. This suggests that the size of $\mathrm{Bu}_{4} \mathrm{~N}^{+}$dominates in the determination of interionic separation. Further studies are planned to investigate this phenomenon.

Damage and desorption yield effects. As can be seen in Figure 3 , for salts higher in mass than $\mathrm{Bu}_{4} \mathrm{~N}^{+}$the relative intensities begin to deviate from the simple behavior predicted by Coulomb's law. Using the data in Figure 4 as a guide to predict that the ionization efficiencies of the larger salts should not be greatly different, a secondary effect must be causing the observed decrease in relative ion signal intensities. Ens et al [27] have also observed decreasing ion yields for higher mass biological compounds (556 to $5733 \mathrm{Da}$ ), but an explanation for the decrease was not given. The decrease likely results from two phenomena: an increase in sputter-induced damage to the parent molecule and/or a reduction in desorption yield.

A useful method for studying damage and desorption is to plot the secondary ion intensities of a species 
of interest as a function of primary ion dose to produce a decay curve. Figure 5 shows the normalized intact cation decay curves for the eight detectable salts in the gelatin matrix. The slope of each curve represents the disappearance cross section, $\sigma$, defined as:

$$
\sigma=\left[-\ln \left(\frac{N(t)}{N(0)}\right)\right] / v t
$$

where $N(0)$ is the initial integrated intensity under the peak of interest, $N(t)$ is the integrated intensity at time $=\mathrm{t}$ (seconds), and $v$ is the primary ion flux density (ions $\mathrm{cm}^{-2} \mathrm{~s}^{-1}$ ) [6]. In studies involving limited sample material (e.g., monolayer or submonolayer coverages on surfaces), the decrease in molecular ion intensities observed with increasing dose is usually assumed to result from sputter removal of the material. In this case the disappearance cross section represents the sputter rate. However, for a bulk sample (like a thick gelatin film) exposed to the range of primary ion doses used in this study, the loss of signal due to complete sputter removal of all molecules can be neglected. Therefore, the disappearance cross section represents the build-up of sputter damage and/or the decrease in sputter yield. The disappearance cross sections calculated from the results shown in Figure 5 are listed in Table 1. The cross sections show a nearly linear increase with increasing mass. The increase in $\sigma$ with increasing mass has also been observed for polystyrene oligomers [28]. The relatively high values of $\sigma$ for the heaviest salts indicate that the intact cations disappear faster than those of the lower mass salts (i.e., damage accumulates faster). Therefore, we would expect the relative intact cation intensity of Dode ${ }_{4} \mathrm{~N}^{+}$to be lower than $\mathrm{Bu}_{4} \mathrm{~N}^{+}$after prolonged sputtering. For data collected prior to the accumulation of significant damage (static SIMS conditions) we would expect intact cation intensities from light and heavy salts to be about the same, assuming equimolar

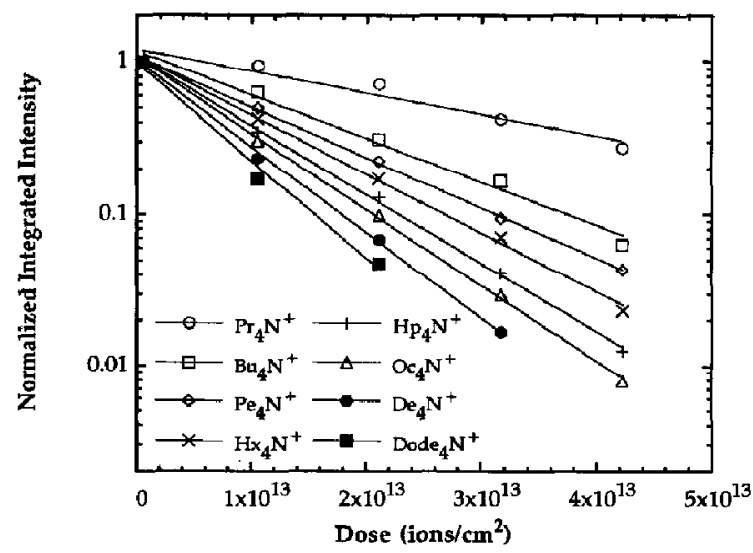

Figure 5. Normalized decay curves for a mixture of eight tetraalkylammonium salts in a gelatin matrix. concentrations and similar ionization efficiencies and allowing for differences in fragmentation. However, as mentioned earlier, the intensity differences noted between $\mathrm{Bu}_{4} \mathrm{~N}^{+}$and Dode ${ }_{4} \mathrm{~N}^{+}$cannot be accounted for by fragmentation alone. This suggests that the sputter (desorption) yield is decreasing with increasing mass.

To further explain the differences between the relative intensities of low and high mass cations, it is necessary to discuss the origin of intact cation and fragment ions during ion bombardment. For tetraalkylammonium salts, intact cation formation is thought to occur either through direct emission of cations by momentum transfer [29] or by dissociation in the gas phase above the surface after ejection of a neutral species [24]. Assuming the ionization efficiencies are nearly constant for salts with masses greater than $\mathrm{Bu}_{4} \mathrm{~N}^{+}$, the process exhibiting the most influence on the secondary ion intensities would be the efficiency of desorbing the salt as either an ionic or neutral species (i.e., the desorption yield). It is generally assumed that on a macroscopic scale the sputter yield of a dilute dopant is controlled by the sputter yield of the matrix. In the doped gelatin samples the overall erosion rate may well be governed by the sputter yield of the gelatin, but on the scale of a single ion impact the ability to desorb the relatively large organic salt from the surrounding matrix will control the secondary ion intensity. Salts with low desorption yields would have low relative intensities. Therefore, the data in Figure 3 suggest that the desorption yields are decreasing with increasing cation mass above $\mathrm{Bu}_{4} \mathrm{~N}^{+}$. Further evidence for the decrease in desorption yields with increasing mass can be found in the fragment-to-cation ratios plotted as a function of primary ion dose (Figure 6). The fragment-to-cation ratios for each compound show a nearly linear increase in fragmentation with increasing dose. The slopes of the lines are listed in Table 1. The increasing ratios, along with the disap-

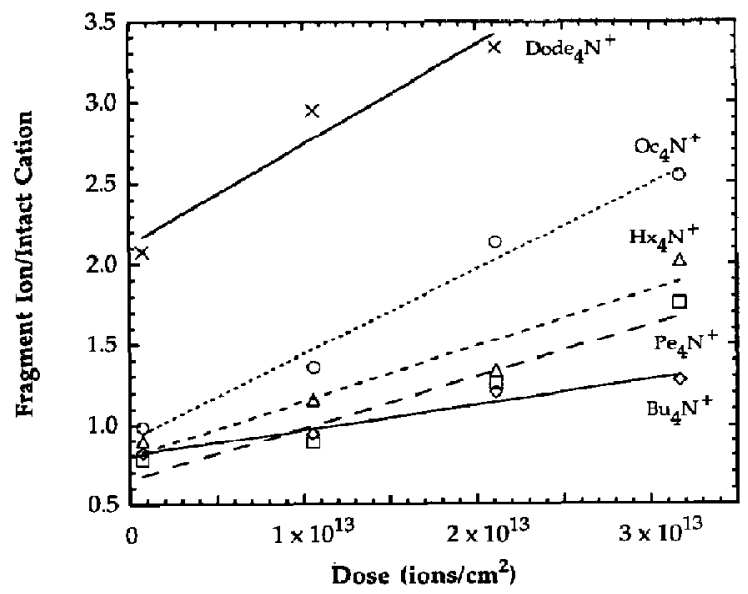

Figure 6. Ratio of the iminium ion signal intensity to intact cation signal intensity for five tetraalkylammonium salts in a gelatin matrix as a function of primary ion dose. 
pearance cross section data, indicate that the accumulation of damage leads to increased fragmentation. Fragmentation can occur either at the point of impact or as a result of unimolecular decomposition in the gas phase. Gillen [22] reported that gas-phase fragmentation can account for up to $50 \%$ of the fragment ion signal coming from sputtered $\mathrm{Bu}_{4} \mathrm{~N}^{+}$. No matter which fragmentation process is assumed, the effects will be the same. If the dominant fragmentation pathway is surface related, then at the point of a single ion impact a low desorption yield reduces the likelihood of direct cation or neutral emission and increases the chance of fragmentation. If unimolecular decomposition is the dominant process, a low desorption yield would reduce the number of intact cations present above the surface where fragmentation occurs. In either case the result is the same: damage would accumulate fastest in salts with the lowest desorption yields [30].

Concentration effects. Another factor influencing the relative intensities of tetraalkyl cations is the total salt concentration in the gelatin matrix. Results from earlier quantitative studies of tetraalkylammonium salts in gelatin indicated that at relatively high saltin-gelatin concentrations $(0.01 \mathrm{~g} / \mathrm{g}$ or higher) saturation of the intact cation signal can occur [15]. This same behavior has also been observed for polystyrene solutions deposited on Ag [28]. To investigate the extent of concentration-related intact cation suppression in salt-gelatin mixtures, we prepared an equimolar mixture of the salts $\mathrm{Pr}_{4} \mathrm{~N}^{+}, \mathrm{Bu}_{4} \mathrm{~N}^{+}, \mathrm{Pe}_{4} \mathrm{~N}^{+}$and $\mathrm{Hx}_{4} \mathrm{~N}^{\prime}$ and added it to the gelatin at total salt concentrations ranging from $0.0014 \mathrm{~g} / \mathrm{g}$ to $0.14 \mathrm{~g} / \mathrm{g}$. The average absolute integrated intact cation signal intensities for the four salts at the different concentrations are shown in Figure 7 . The error bars represent the standard deviations (s) of the individual measurements from five mass spectra. The trend observed for the lowest concentration sample in Figure 7 is similar to

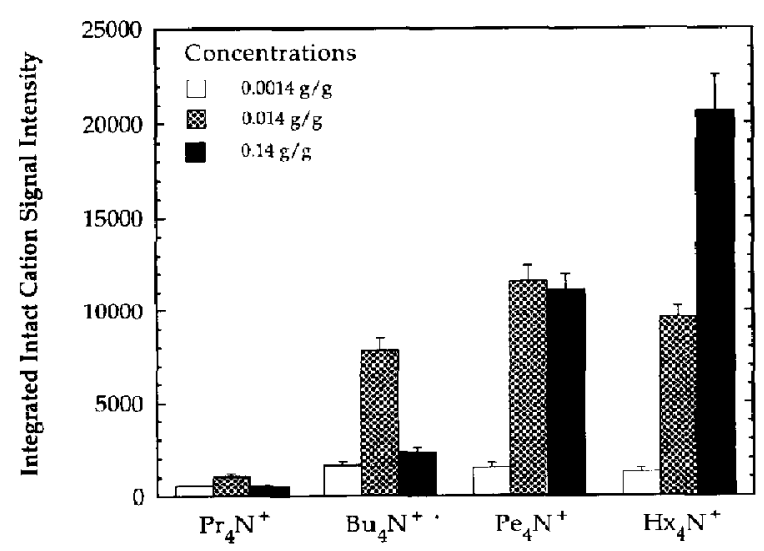

Figure 7. Average absolute integrated intact cation signal intensities from an equimolar mixture of four tetraalkylammonium salts in gelatin as a function of total salt concentration. that seen for the same four salts in Figure 3. The concentrations of the samples used to acquire the data used in Figure 3 are within a factor of three of the lowest concentration sample in Figure 7. As can be seen in Figure 7 , when the total salt content increases from $0.0014 \mathrm{~g} / \mathrm{g}$ to $0.014 \mathrm{~g} / \mathrm{g}$, the absolute intensities of $\mathrm{Pr}_{4} \mathrm{~N}^{+}$and $\mathrm{Bu}_{4} \mathrm{~N}^{+}$increased by less than the expected factor of 10 (2.0 and 4.8, respectively). $\mathrm{Pe}_{4} \mathrm{~N}^{+}$ and $\mathrm{Hx}_{4} \mathrm{~N}^{+}$increased by almost a factor of eight. After an increase in concentration from $0.014 \mathrm{~g} / \mathrm{g}$ to $0.14 \mathrm{~g} / \mathrm{g}$ the absolute ion signal intensities of $\mathrm{Pr}_{1} \mathrm{~N}^{+}$ and $\mathrm{Bu}_{4} \mathrm{~N}^{-1}$ actually decrease while $\mathrm{Pe}_{4} \mathrm{~N}^{+}$remains constant. At the same time the average absolute ion signal intensity of $\mathrm{Hx}_{4} \mathrm{~N}^{+}$increased by only a factor of 2 suggesting that $\mathrm{Hx}_{4} \mathrm{~N}^{+}$was also being suppressed. For the concentrations $0.0014 \mathrm{~g} / \mathrm{g}$ and $0.014 \mathrm{~g} / \mathrm{g}$ the fragment-to-cation ratios for $\mathrm{Bu}_{4} \mathrm{~N}^{+}, \mathrm{Pe}_{4} \mathrm{~N}^{+}$, and $\mathrm{Hx}_{4} \mathrm{~N}^{+}$were very similar to the values listed in Table 1. However, the ratios for $\mathrm{Pe}_{4} \mathrm{~N}^{+}$and $\mathrm{Hx}_{4} \mathrm{~N}^{+}$obtained from the $0.14 \mathrm{~g} / \mathrm{g}$ sample decreased to 0.46 and 0.55 , respectively. This suggests that fragmentation is also affected by increases in salt concentration. Incidentally, the plot of the $0.14 \mathrm{~g} / \mathrm{g}$ intact cation intensities closely resembles the trends observed by Colton and co-workers [24] for a neat mixture of $\mathrm{Et}_{4} \mathrm{~N}^{+}$, $\mathrm{Pr}_{4} \mathrm{~N}^{+}, \mathrm{Bu}_{4} \mathrm{~N}^{+}$, and $\mathrm{Pe}_{4} \mathrm{~N}^{+}$in which a steady increase in relative intensities was observed from $\mathrm{Et}_{4} \mathrm{~N}^{+}$to $\mathrm{Bu}_{4} \mathrm{~N}^{+}$.

\section{Summary}

The produclion of secondary ions from tetraalkyl salts in a gelatin matrix is obviously a complex process influenced by several factors. For low-mass salts $\left(E_{4} \mathrm{~N}^{+}\right.$and $\left.\mathbf{P r}_{4} \mathrm{~N}^{+}\right)$the strong ionic bond between the organic cation and the counterion inhibits the formation of intact cations. Whether the suppression of cation signal from low-mass salts is due to the inability to break the cation-counterion bond or is the result of reneutralization of the cation by the counterion is not clear. However, the suppression of the cation signal from low-mass salts as a function of increasing salt concentration suggests that reneutralization by excess counterions is a possibility. This hypothesis is under investigation. From the coulombic force expression we would expect the salt ion yields to increase with mass until the point where the charge separation is sutficiently large to create a nearly constant ionization efficiency. This should occur for salts larger than $\mathrm{Pe}_{4} \mathrm{~N}^{+}$. However, the relative intact cation signals decrease with increasing mass from $P_{4} N^{+}$to Dode ${ }_{4} N^{+}$. This effect has also been observed for polymers and high mass biological compounds. This is likely due to the decrease in desorption yields with increasing mass. It is also possible that the gelatin matrix selectively binds to the higher mass molecules, thereby reducing the desorption yield. The increased disappearance rate, as reflected in the decay curves, and the increased proportion of fragmentation for the larger salts sug- 
gests that a low desorption yield is allowing damage to accumulate faster for the larger salts than for the smaller salts.

The parameters that govern the formation and emission of secondary ions from tetraalkylammonium salts dispersed in a gelatin matrix are likely to be relevant to more analytically important systems (e.g., organic compounds in biological tissue), except that not all compounds will be present as preformed salts. Detection of the species of interest will surely depend on optimization of the experimental conditions that combine to give the highest secondary ion signal. For all but the smallest salts, ionization efficiencies may already be maximized due to the large charge separation in larger molecules. Therefore, the parameters that will affect secondary ion intensities most will be desorption yield and damage accumulation. This work suggests that with tissuelike matrices there may be a limited range of molecule sizes (or masses) which will provide maximum secondary ion intensities and, therefore, will have the highest detection sensitivity. This study also suggests that concentration-related suppression of secondary ions can affect detection sensitivities.

Additional studies are necessary to identify the reasons for the suppression of secondary ion intensities with increasing salt concentration as well as the apparent lowering of the desorption yield with increasing mass. Gaining a better understanding of the fundamental faclors influencing the formation and enission of tetraalkylammonium ions from gelatin will ultimately improve the prospects of detecting biologically important species in tissue and tissuelike matrices. We are continuing to explore methods for increasing the secondary ion yields of organic molecules (preformed salts and neutral species) as well as ways of decreasing damage accumulation. Success in both areas would surely extend the capabilities of SIMS in biological and biomedical applications.

\section{References}

1. Benringhoven, A.; Sichtermann, W. K. Anal. Chem. 1978, 50, 1180

2. Grade, H.; Winograd, N.; Cooks, R. G. I. Am. Chem. Soc. 1977, 99,7725 .

3. Briggs, D. Surf. Interface Anal. 1986, 9, 391.

4. Kidwell, D. A.; Ross, M. M; Colton, R, J. Bioned. Mass Spectrom. 1985, 12, 254.
5. Lub, J.; van der Wel, H. In Secondary Ion Mass Spectronetry, SIMS VII; Benninghoven, A.; Evans, C. A.; McKeegan, K. D.; Storms, H. A.; Werner, H. W., Eds.; Wiley: Chichester, 1990; p 305.

6. Benninghoven, $A_{4} ;$ Rudenauer, F. G; Werner, H. W. Secondary Ion Mass Spectrometry; Wiley: New York, 1987; pp 671-678.

7. Lange, W; Jirikowsky, $M_{\text {; }}$ Benninghoven, A. Surface Sci. $1984,136,419$.

8. Cooks, R. G.; Busch, K. L. Int. I. Mass Spectrom. Ion Phys. $1983,53,111$.

9. Ross, M. M.; Colton, R. J. Anal. Chem. 1983, 55, 150.

10. Lee, M. S.; Moon, S. L.; Combs, C.; Rosenberg, I. E.; Odom, R. W.; Schueler, B.; Chakel, J. A. Proceedings of the 38th Annual ASMS Conference on Mass Spectrometry and Allied Topics; Tucson, AZ, 1990; p 696.

11. Todd, P. J.; Short, R. T.; Grimm, C. C.; Holland, W. M. Proceedings of the 40th Annual ASMS Conference on Mass Spectrometry and Allied Topics; Washington, DC, 1992; 1961.

12. Burns-tiellhorn, M.; Hile, D. M. Anal. Biochem. 1979, 92, 213.

13. Gillen, G. Proceedings of the 39th Anmual ASMS Conference on Mass Spectrometry and Allied Topics; Nashville, TN, 1991; p 1141.

14. John, C. M.; Chakel, J. A.; Schueler, B.; Odom, R. W. Proceedings of the 39th Annual ASMS Conference on Mass Spectrometry and Allied Topics: Nashville, TN, 1991; p 27.

15. Gillen, G.; Hues, S. J. Am. Soc. Mass Spectrom. 1993, 4, 419.

16. Unger, S. E.; Ryan, T. M.; Cooks, R. G. Anal. Chim. Acta 1980, $118,169$.

17. Busch, K. L.; Hsu, B. H.; Xie, Y.-X.; Cooks, R. G. Anal. Chem. $1983,55,1157$.

18. Gierlich, H. H.; Röllgen, F. W.; Borchers, F.; Levsen, K. Org. Mass Spectrom. 1977, 12, 387.

19. Veith, H, J. Org, Mass Spectrom. 1978, 13, 280.

20. Veith, H. J. Org. Mass Spectrom. 1983, 18, 154.

21. Schueler, B.; Krueger, F. R. Org. Mass Spectrom. 1979, 14, 439.

22. Gillen, G. Int. J. Mass Spectrom. Ion Processes 1991, 105, 215.

23. Cotton, F.A.; Wilkerson, G. Advanced Inorganic Chemistry, 4th ed.; Wiley; New York, 1980; p 20.

24. Kidwell, D. A.; Ross, M. M.; Colton, R. J. Int. J. Mass Spectrom. Ion Processes 1987, 78, 315.

25. Rabinson, R. A.: Stokes, R. H. Electralyte Solutions, 2nd ed.; Academic: New York, 1959; p 124.

26. Harned, H. S.; Owen, B. B. The Physical Chenistry of Electrolytic Solutions, 3rd ed; Reinhold: New York, 1958; p 703.

27. Ens, W.; Chait, B.; Beavis, R.; Main, D.; Tang, X. Proceedings of the 34th Anuual ASMS Conference on Mass Spectrometry and Allied Topics; Cincirnati, OH, 1986; $\mathrm{p} 643$.

28. van Leyen, D; Hagenhoff, $B$; Niehuis, E.; Benninghoven, A.; Blestos, I. V; Hercules, D. M. J. Vac. Sci. Technol. A 1989, 7, 1790.

29. Day, R. J.; Unger, S. E.; Cooks, R. G. Anal. Chem. 1980, 52, $557 \mathrm{~A}$.

30. Gillen, G.; Simons, D. S.; Williams, P. Anal. Chem. 1990, 62, 2122. 